\title{
Vertical profiles of dust and other aerosol types above a coastal site
}

\author{
Dietrich Althausen ${ }^{1, *}$, Silke Mewes ${ }^{1,2}$, Birgit Heese ${ }^{1}$, Julian Hofer ${ }^{1}$, Yoav Schechner ${ }^{3}$, Amit Aides ${ }^{3}$, and Vadim \\ Holodovsky $^{3}$ \\ ${ }^{1}$ Leibniz Institute for Tropospheric Research, Permoserstr. 15, 04318 Leipzig, Germany \\ ${ }^{2}$ University of Leipzig, Leipziger Institut für Meteorologie, Stephanstr. 3, 04103 Leipzig, Germany \\ ${ }^{3}$ Technion - Israel Institute of Technology, Viterbi Faculty of Electrical Engineering, Haifa 3200003, Israel
}

\begin{abstract}
Monthly mean vertical profiles of aerosol type occurrences are determined from multiwavelength Raman and polarization lidar measurements above Haifa, Israel, in 2017. This contribution presents the applied methods and threshold values. The results are discussed for one example, May 2017. This month shows more often large, non-spherical particles in lofted layers than within the planetary boundary layer. Small particles are observed at higher altitudes only when they are observed in lower altitudes, too.
\end{abstract}

\section{Introduction}

Israel is often affected by dust that is transported towards the country, mainly from the deserts around it as investigated by Israelevich et al. [1]. These dust events are related to distinguished weather patterns as explored for example by Dayan et al. [2]. But these investigations often base on measurements at ground only. To determine the whole vertical extend of the dust events height-resolved remote measurements are very suitable.

The sources of mineral dust layers are usually deserts or dried lakes etc. The dust is uplifted within the planetary boundary layer (PBL) and advected to neighboring sites. Coastal sites act as interfaces between the typically thicker daytime PBL above land and the thinner daytime PBL over sea. The advection of particle loaded airmasses may therefore cause parts of the continental PBL to slide above the marine PBL. This might be one reason for particle layers in the free troposphere. Furthermore, large cities are often located close to the coastline, which causes additionally vertical mixing of urban particles at coastal sites.

The question arises, whether there are advected particle layers that are only in the free troposphere above coastal sites? And, in case of there are particle layers, what particle types are present in the lofted particle layers?

Technion - Israel Institute of Technology and Leibniz Institute for Tropospheric Research (TROPOS) cooperate in the frame of the project "3D Widefield Sky Scatterer Tomography by Lidar Anchor". This project is funded by the German-Israeli Foundation for Scientific Research and Development (GIF) from 2015 until the end of 2018 and aims at the observation of dust layers by different instruments and thus different techniques. The project includes also continuous (24/7) height-resolved measurements of the vertical aerosol structure above the coastal site Haifa,
Israel, by a multiwavelength Raman and polarization lidar Polly XT.

The next chapter refers to the measurement site, the utilized lidar, and describes the data retrieval methods and outputs. Chapter 3 deals with observed aerosol types and lists those intensive particle properties that are used for the aerosol type characterization. The monthly mean vertical profile from May 2017 will be presented as an example in chapter 4 . A summary concludes the paper.

\section{Measurement site, measurement system, and for data retrieval methods}

The multiwavelength Raman and polarization lidar Polly ${ }^{\mathrm{XT}}[3,4]$ was installed in Haifa in March 2017. The measurement site is located at $\mathrm{N} 32.8^{\circ}, \mathrm{E} 35.0^{\circ}$ and has a height above sea level of $230 \mathrm{~m}$. Since Haifa is a coastal site, the closest distance to the sea is about 4 to $5 \mathrm{~km}$. Figure 1 shows the lidar system on the platform as well as the sun photometer on the right top of the safety fence around the system.

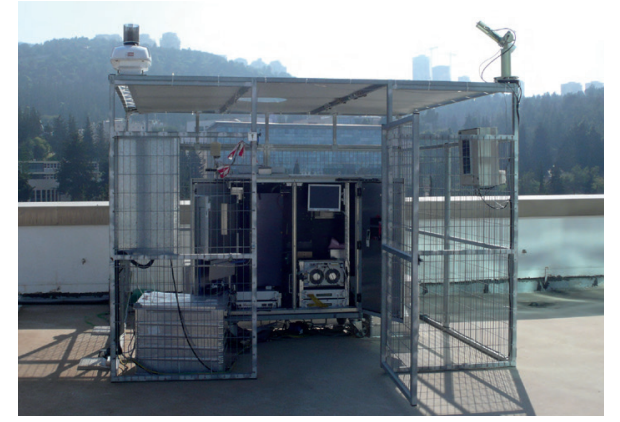

Figure 1. Measurement site with multiwavelength lidar Polly ${ }^{\mathrm{XT}}$ at the rooftop of the Electrical Engineering building of Technion.

*Corresponding author: dietrich@tropos.de 
The lidar emits laser pulses at 1064, 532, and $355 \mathrm{~nm}$ wavelengths $(\lambda)$. It has 2 receivers: one for near-range and one for far-range detection. The far-range detection receiver consists of eight channels, as follows. Three channels measure the elastic signals at the 355,532 , and $1064 \mathrm{~nm}$ wavelengths. Two channels measure inelastic signals at 387 and $607 \mathrm{~nm}$ wavelengths, which correspond to vibrational-rotational Raman scattering by $\mathrm{N}_{2}$ molecules of light at 355 and $532 \mathrm{~nm}$ wavelength, respectively. Two channels measure the cross-polarized signals at 355 and $532 \mathrm{~nm}$ wavelengths, and one channel measures the vibrational-rotational Raman inelastic signal from water vapor at $407 \mathrm{~nm}$ wavelength. The near-range receiver has four detectors for the measurement of the elastic and inelastic $\left(\mathrm{N}_{2}\right)$ signals in the visible and ultra-violet ranges.

The extensive particle quantities, the backscatter coefficient $\beta_{\mathrm{par}}(\lambda)$ and the extinction coefficient $\alpha_{\mathrm{par}}(\lambda)$, are determined from the data of these 12 channels. For this study, the following interesting intensive quantities are obtained: the lidar ratio at 532 and $355 \mathrm{~nm}$ wavelengths $S_{\text {par }}(532)$ and $S_{\text {par }}(355)$, the particle depolarization ratio at 532 and $355 \mathrm{~nm}$ wavelengths $\delta_{\mathrm{par}}(532)$ and $\delta_{\mathrm{par}}(355)$, the ratios of the particle backscatter coefficient at different wavelengths, and the backscatter-related Ångström exponent $\AA_{\text {par }, \beta, 532,1064}=$ $\ln \left(\beta_{\text {par }}(532) / \beta_{\text {par }}(1064)\right) / \ln (1064 / 532)[5,6]$. Baars et al. [7] introduced the "quasi" particle backscatter coefficient ${ }_{\text {quasi }} \beta_{\text {par }}(\lambda)$ in neglecting the particle attenuation in the retrieval algorithms. This first guess is possible for aerosol optical thicknesses that are smaller than 0.2 [8]. For such low aerosol optical thicknesses, the "quasi"-quantities ( $\left.{ }^{\text {quasi }} \beta_{\text {par }}(1064), \delta_{\text {par }}(532), \AA_{\text {par, } \beta, 532,1064)}\right)$ are equal within the errors to their respective ("non-quasi") quantities.

\section{Aerosol type characterization}

Atmospheric particles differ in their properties as they origin from different sources. Seinfeld and Pandis [9] distinguish between the following ambient aerosol types: urban, marine, rural continental, remote continental, free troposphere, polar, and desert aerosols. These types have different micro-physical and optical properties.

Recent developments of height-resolved measuring aerosol lidar techniques allow new insights into atmospheric particle layers. Applications show, that the quantities and the ranges for the threshold values need further improvements.

Burton et al. [10] used lidar data from airborne measurement campaigns at the North-American continent with partly known origin, especially the four intensive quantities $\delta_{\mathrm{par}}(532), S_{\mathrm{par}}(532), \beta_{\mathrm{par}}(532) / \beta_{\mathrm{par}}(1064)$, and $\delta_{\text {par }}(1064) / \delta_{\text {par }}(532)$. They spanned a 4-dimensional space to distinguish between eight aerosol types: smoke, fresh smoke, urban, polluted maritime, maritime, dusty mix, pure dust, and ice. Groß et al. [11] used data with known origin. These data were taken in Europe and Africa. By this, they could derive the ranges of $\delta_{\text {par }}(532), S_{\text {par }}(532)$, and $\beta_{\mathrm{par}}(532) / \beta_{\mathrm{par}}(1064)$ for the atmospheric particles of the following types: Saharan dust, Canadian biomass burning aerosol (aged), anthropogenic pollution, mixed
Table 1. Applied criteria for particle type characterization [7].

\begin{tabular}{lll}
\hline Aerosol type & Parameter & Value \\
\hline \hline small & quasi $\beta_{\text {par }}(1064)$ & $>2 \times 10^{-7} \mathrm{~m}^{-1} \mathrm{sr}^{-1}$ \\
(urban) & ${ }_{\text {quasi }} \delta_{\text {par }}(532)$ & $<0.07$ \\
& ${ }_{\text {quasi }} A_{\text {par, }, \beta, 532,1064}$ & $\geq 0.75$ \\
\hline large, & ${ }_{\text {quasi }} \beta_{\text {par }}(1064)$ & $>2 \times 10^{-7} \mathrm{~m}^{-1} \mathrm{sr}^{-1}$ \\
spherical & ${ }_{\text {quasi }} \delta_{\text {par }}(532)$ & $<0.07$ \\
(marine) & ${ }_{\text {quasi }} A_{\text {par, }, \beta, 532,1064}$ & $<0.75$ \\
\hline mixture, partly & ${ }^{\text {quasi }} \beta_{\text {par }}(1064)$ & $>2 \times 10^{-7} \mathrm{~m}^{-1} \mathrm{sr}^{-1}$ \\
non-spherical & ${ }_{\text {quasi }} \delta_{\text {par }}(532)$ & $\geq 0.07,<0.20$ \\
\hline $\begin{array}{l}\text { large, } \\
\text { non-spherical } \\
\text { (dust) }\end{array}$ & ${ }_{\text {quasi }}{ }_{\text {quasi }} \delta_{\text {par }}(1064)$ & $>2 \times 10^{-7} \mathrm{~m}^{-1} \mathrm{sr}^{-1}$ \\
\hline \hline
\end{tabular}

Saharan dust, African biomass burning mix, and marine aerosol. More publications on this issue were published, all related to a certain region of the globe. But so far, the aerosol types in Israel have not been investigated by remote-sensing multiwavelengths Raman and polarization lidar systems.

Before reaching Haifa, the pathways of air parcel transports are often over-crossing deserts. The metropolis Haifa is itself a city with a lot of industrial activities. Hence, it is expected that the main aerosol types are marine, dust, urban aerosol, and consequently also mixtures of them. Especially the definition of a mixture by using phenomenological, observable quantities needs more investigations with different approaches and methods for new locations. As a first guess, the practical threshold values of Baars et al. [7] had been used for $\beta_{\text {par }}$ (1064), $\delta_{\text {par }}(532)$, and $\AA_{\text {par, } \beta, 532,1064}$ to distinguish between the different particle types and are listed in Table 1.

\section{Example: Vertical profile of particles types during May 2017}

The retrieval of the atmospheric data from the lidar measurements underwent several steps. First, a cloud screening was done to avoid cloud contaminated results. Secondly, only Raman measurements were used to ensure good data quality and less/no influence of the incomplete overlap between the divergence and angle of the emitted beam and the receiver field of view. It has to be noted that only nighttime measurements are used for the May data by this procedure.

Aerosol layers are easily identified from lidar profiles. The heights of those layers were determined by the largest gradients of the range-corrected-signal profile in the respective range. The layers above the PBL are numbered consecutively as they occur: Layer 1, Layer 2, Layer3. During May, 16 times at least one layer has been observed above the PBL. Out of these 16 times, there appeared a second layer above the PBL in 10 instances. Out of these 10 times, a third layer above the PBL was detected in 6 instances. The height ranges for these layers are shown in Fig. 2. The ranges of the lofted layers may overlap due to the retrieval procedure. The layer height ranges show that the first layer above the PBL was always below $5 \mathrm{~km}$ 


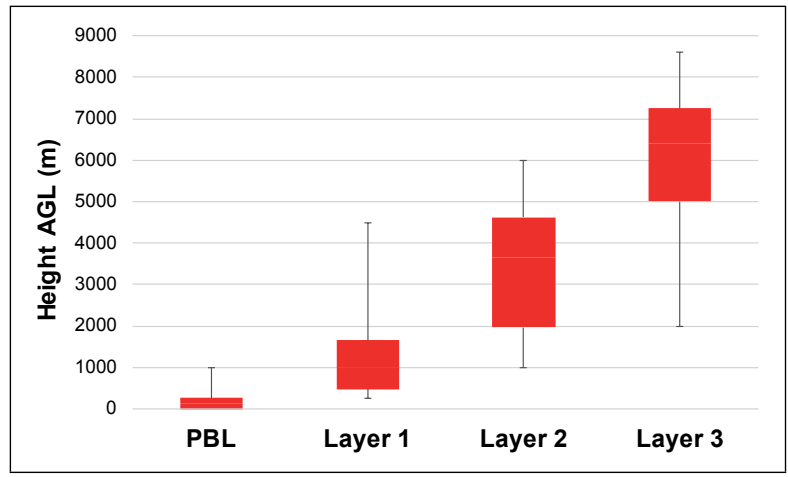

Figure 2. Height ranges of aerosol layers during May 2017. The red box indicates the range for $25 \%$ to $75 \%$ of all layers of the respective layer combination.

height and that the highest layers were observed mostly when lower layers were present.

The aerosol type occurrences were counted in vertical intervals of $500 \mathrm{~m}$ to get the monthly mean profile of the frequency of occurrence of the aerosol types. These $500 \mathrm{~m}$ interval steps are well above $247 \mathrm{~m}$, which is the vertical smoothing length within the lidar retrieval algorithm. On the other hand, these $500 \mathrm{~m}$ interval steps are not related to the vertical air density profile or the height of the PBL. Often, the height of the PBL was $<500 \mathrm{~m}$. It took place, that the first layer above the PBL ranged from a height of $250 \mathrm{~m}$ to a height of $1400 \mathrm{~m}$. In such a case, the aerosol type of this (first) layer was attributed to (counted in) the height intervals $<500 \mathrm{~m},<1000 \mathrm{~m}$, and $<1500 \mathrm{~m}$. Hence the aerosol type of the PBL and the aerosol type of the first layer are both counted in the height interval $<500 \mathrm{~m}$. This yields for the interval $<500 \mathrm{~m}$ that the resulting number of aerosol types is larger than the number of profiles.

In May 2017, 16 vertical profiles were retrieved after the cloud screening. Out of this 16 profiles, in height ranges $<500 \mathrm{~m}$ an aerosol type was identified 24 times since 8 times also the first layer above the PBL ranged below $<500 \mathrm{~m}$. This maximum number of aerosol type identifications was used to normalize the vertical profiles of the height-dependent frequency of aerosol type occurrences. Figure 3 shows the resulting vertical profile of the frequency of aerosol type occurrences.

The profile shows that above $1500 \mathrm{~m}$ height the frequency of occurrence of any aerosol type is $50 \%$ or less compared to the number of aerosol type observations $<500 \mathrm{~m}$. Looking at the height ranges between $3000 \mathrm{~m}$ and $3500 \mathrm{~m}, 80 \%$ of all observations indicate large, nonspherical particles above Haifa. It is also obvious, that the aerosol type "large, non-spherical" is observed more times in lofted layers than in the height ranges $<500 \mathrm{~m}$. The aerosol type "small" is only observed in lofted layers if the lofted layers existed in heights $<500 \mathrm{~m}$. This is reasonable when having in mind the vertical mixing either by turbulence before the measurements or by advection from other (possibly neighboring) sites. During May 2017 the aerosol type "large, spherical" (likely marine) was not observed although the wind pattern showed westerly winds

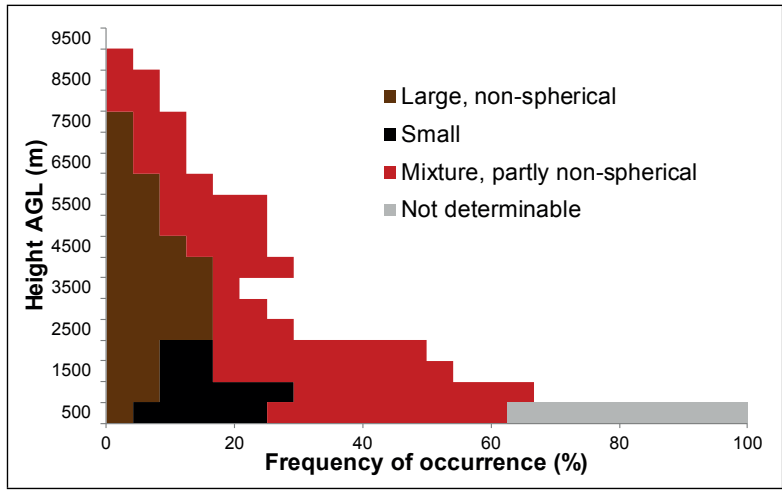

Figure 3. Height-dependent occurrence of aerosol types during May 2017.

during which this aerosol type is normally expected. Further studies are needed to understand this observations.

\section{Summary}

For the first time, continuous (24/7) height-resolved measurements of the vertical aerosol structure were taken above the coastal site Haifa, Israel, by a multiwavelength Raman and polarization lidar. The measured intensive optical particle properties were used to identify the different particle types. It is shown that there are lofted layers in the free troposphere above this coastal site and that those layers contain either large, non-spherical particles or a mixture of those with other particles.

As an example, the monthly mean aerosol type occurrence profile of May 2017 is presented. The most abundant particle type is that of "mixture, partly non-spherical". But this is a very generalized aerosol type, which is of course also caused by the selection of the threshold values. A next step in this investigation would be to use more specific threshold values and/ or to introduce additional intensive properties. This might yield to a more specific particle type characterization in future.

Acknowledgments: This project is funded by the GermanIsraeli Foundation (GIF grant I-1262-401.10/2014) with support of the Norman and Helen Asher Fund. The work of Yoav Y. Schechner is conducted in the Ollendorff Minerva Center. Minerva is funded through the BMBF (German federal ministry for education and research). TROPOS has also received funding from the European Union's Horizon 2020 research and innovation program under grant agreement No 654109.

\section{References}

[1] P.L. Israelevich, E. Ganor, Z. Levin, and J. H. Joseph, J. Geophys. Res. 108, 4381-4389 (2003)

[2] U. Dayan, B. Ziv, T. Shoob, V. Enzel, Int. J. Climatol. 28, 915-924 (2008)

[3] D. Althausen, R. Engelmann, H. Baars, B. Heese, A. Ansmann, D. Müller, M. Komppula, J. Atmos. Oceanic Technol. 26, 2366-2378 (2009) 
[4] R. Engelmann, T. Kanitz, H. Baars, B. Heese, D. Althausen, A. Skupin, U. Wandinger, M. Komppula, I.S. Stachlewska, V. Amiridis, E. Marinou, I. Mattis, H. Linné, A. Ansmann, A., Atmos. Meas. Tech. 9, 1767-1784 (2016)

[5] Claus Weitkamp, (ed.), Range-Resolved Optical Remote Sensing of the Atmosphere (Springer, New York, 2005) 456 pages

[6] V. Freudenthaler, M. Esselborn, M. Wiegner, B. Heese, M. Tesche, A. Ansmann, D. Müller, D. Althausen, M. Wirth, A. Fix, G. Ehret, P. Knippertz, C. Toledano, J. Gasteiger, M. Garhammer, M. Seefeldner, Tellus B: Chem. Phys. Meteor. 61B(1), 165-179 (2009)
[7] H. Baars, P. Seifert, R. Engelmann, U. Wandinger, Atmos. Meas. Tech. 10, 3175-3201 (2017)

[8] Baars: personal communication

[9] John H. Seinfeld and Spyros N. Pandis, Atmospheric chemistry and physics, from air pollution to climate change (John Wiley \& Sons, Inc., New York, 1998) 1326 pages

[10] S.P. Burton, R.A. Ferrare, C.A. Hostetler, J.W. Hair, R.R. Rogers, M.D. Obland, C.F. Butler, A.L. Cook, D.B. Harper, K. D. Froyd, Atmos. Meas. Tech. 5, 7398 (2012)

[11] S. Groß, M. Esselborn, B. Weinzierl, M. Wirth, A. Fix, A. Petzold, Atmos. Chem. Phys. 13, 2487-2505 (2013) 